\title{
EVALUASI SISTEM INFORMASI AKUNTANSI PENGENDALIAN KAS \\ BERBASIS KOMPUTER PADA PERUSAHAAN \\ INTERNET SERVICE PROVIDER \\ (STUDI KASUS PENERAPAN APLIKASI MYOB V 13+ \\ DI PT.LDP YOGYAKARTA)
}

\author{
Elly Astuti \\ Elva Nuraina \\ elvanuraina@yahoo.co.id
}

\begin{abstract}
The purpose of writing this paper is to evaluate the computer-based accounting system that has been used by PT. LDP for decision making by the parties concerned as well as provide additional references for further research. Data were obtained from interviews with the board of directors with miraculous and financial staff associated with the implementation of MYOB applications in PT. LDP Yogyakarta in 2011. The result shows that the use of MYOB accounting information systems has positive impact on the company's financial statement presentation primary for its timelines. However, the evaluation of the application system, there are some things that need to be repaired by PT. LDP so the accounting information that presented can be used for economic decision-making. Implications for further research is the design and development of internal control system for family owned businesses.
\end{abstract}

\begin{abstract}
ABSTRAK
Tujuan penulisan paper ini adalah untuk mengevaluasi sistem akuntansi berbasis komputer yang telah digunakan PT. LDP agar dapat digunakan sebagai bahan pertimbangan pengambilan keputusan oleh pihak-pihak yang berkepentingan serta memberikan tambahan referensi bagi penelitian lebih lanjut. Data penelitian diperoleh dari intervieu dengan beberapa dewan direksi serta staf keuangan yang terkait dengan penerapan aplikasi MYOB di PT. LDP Yogyakarta pada tahun 2011 setelah aplikasi program berjalan 1 tahun. Hasil analisis menunjukkan bahwa penggunaan aplikasi MYOB dalam sistem informasi akuntansi perusahaan berdampak positif terhadap timelines penyajian laporan keuangan perusahaan. Namun pada evaluasi sistem aplikasi tersebut, ada beberapa hal yang perlu diperbaiki oleh PT. LDP agar informasi akuntansi yang disajikan dapat digunakan untuk pengambilan keputusan ekonomik secara cepat dan tepat serta dapat dipertangungjawabkan. Implikasi untuk penelitian lebih lanjut adalah perancangan dan pengembangan sistem pengendalian internal bagi perusahaanperusahaan perorangan.
\end{abstract}

\section{PENDAHULUAN}

Seiring dengan perkembangan teknologi informasi dan globalisasi ekonomi industri, kebutuhan informasi yang berguna bagi pembuatan keputusan ekonomik semakin tinggi. Proses tersebut tentu dihadapkan pada pertimbangan kos dan benefit yang mampu diraih oleh perusahaan. Sebuah solusi ditawarkan oleh beberapa pengembang software sistem informasi akuntansi yang mampu menyajikan informasi 
secara praktis dan tidak membebani keuangan perusahaa diantaranya ; DEA, MYOB, Peachtree dan sebagainya.

Pengembangan sistem informasi akuntansi pada perusahaan jasa biasanya ditekankan pada pengendalian kas karena merupakan aktiva yang sangat penting dan likuid. Definisi kas menurut PSAK (2009 ; 2.3) Kas terdiri atas saldo kas (cash on hand) dan rekening giro (demand deposits). Berdasarkan karakteristik definisi kas tersebut, dapat dikatakan bahwa kas merupakan alat pembayaran yang siap dan bebas dipergunakan untuk membiayai kegiatan operasional perusahaan. Oleh karena itu, pengendalian siklus kas ini sangat diperlukan karena laporan arus kas merupakan salah satu unsur terpenting penyajian laporan keuangan berdasarkan KDDPLK.

PT. LDP Yogyakarta merupakan sebuah perusahaan internet service provider yang sedang berkembang pesat. Seiring dengan pertumbuhannya, PT LDP memerlukan sistem akuntansi utamanya pengendalian kas secara cepat dan tepat agar mampu memberikan informasi yang berguna bagi pengembilan keputusan ekonomik perusahaan.

Pada awal tahun 2010 PT. LDP memutuskan untuk menggunakan sistem informasi akuntansi berbasis komputer dengan MYOB Accounting. Namun demikian dalam perkembangannya penggunaan software tersebut menemui beberapa kendala sehingga perlu pengkajian lebih lanjut mengenai kos dan benefit perusahaan dalam menggunakan software tersebut.

Tujuan penulisan paper ini adalah untuk mengevaluasi sistem akuntansi berbasis komputer yang telah digunakan PT. LDP agar dapat digunakan sebagai bahan pertimbangan pengambilan keputusan oleh pihak-pihak yang berkepentingan serta memberikan tambahan referensi bagi penelitian lebih lanjut.

\section{TELAAH LITERATUR}

\section{Definisi Sistem Informasi A kuntansi}

Ada berbagai definisi sistem informasi akuntansi yang disampaikan oleh beberapa ilmuwan. Namun demikian dalam panyajian paper ini lebih difikuskan pada definisi Bodnar $(2004 ; 3)$ yang menyampaikan bahwa "An accounting information sistem is a collection of resource, such as people and equipment, designed to transform financial and other data into information". Serta definisi dari Nugroho Wijajanto $(2001 ; 4)$ yang menyatakan bahwa sistem informasi akuntansi merupakan susunan berbagai formulir catatan, peralatan, komputer dan berbagai perlengkapan lainnya yang terkoordinasikan secara erat untuk mentransformasikan data keuangan menjadi informasi yang dibutuhkan manajemen.

\section{Pengendalian Kas}

Ernst Young $(2012 ; 5)$ mendefinisikan kas sebagai berikut cash includes not only currency on hand but demand deposits with banks or other financial institutions. Cash also includes other kinds of accounts that have the general characteristics of demand deposits in that the customer may deposit additional funds at any time and also effectively may withdraw funds at any time without prior notice or penalty. All charges and credits to those accounts are cash receipts or payments to both the entity owning the account and the bank holding it. For example, a bank's granting of a loan by crediting the proceeds to a customer's demand deposit account is a cash payment by the bank and a cash receipt of the customer when the entry is made. 
PSAK 2009; 2.3) mendefinisikan kas sebagai saldo kas dan rekening giro. Setara kas (equivalent) adalah investasi yang sifatnya sangat likuid, berjangka pendek dan dengan cepat dapat dijadikan kas dalam jumlah tertentu tanpa menghadapi resiko perubahan nilai yang signifikan.

Berdasarkan kriteria karakteristik kedua definisi diatas, dapat disimpulkan bahwa kas merupakan alat pembayaran yang paling likuid, mudah dipindahtangankan dan tidak dapat dibuktikan kepemilikannya sehingga pengendalian kas sangat diperlukan melalui sistem pengendalian intern yang baik. Pengendalian kas dilakukan pada tiga aktivitas utama ; aktivitas pendanaan, aktivitas investasi dan aktivitas operasi. Dalam penulisan paper ini lebih ditujukan pada pengendalian kas pada aktivitas operasi sehingga lebih fokus terhadap penerimaan dan pengeluaran kas akibat transaksi operasi.

\section{MYOB Accounting}

MYOB Accounting terbentuk dari sebuah ide besar untuk mewujudkan suatu sistem informasi akuntansi yang dapat menyediakan informasi yang bermanfaat. Awal perkembangan MYOB dimulai tahun 1991 hingga saat ini menawarkan berbagai fitur aplikasi yang menarik dan aplikatif. Software akuntansi asal Australia ini mulai dikenal dan diterapkan di berbagai negara mulai tahun 2005, karena sistem akuntansi berbagai jenis bisnis di belahan dunia mampu tercakupi oleh kehadiran aplikasi MYOB di lingkungan entitas bisnis. Disamping itu aplikasi yang user friendly semakin mempercepat perkembanganya(http://myob.com.au; 1258090872813).

PT. LDP Yogyakarta merupakan salah satu perusahaan yang sedang berkembang pesat dan membutuhkan software akuntansi guna penilaian kinerja perusahaan secara tepat dan akurat. Oleh karena beberapa alasan tersebut, PT. LDP Yogyakarta tertarik untuk ikut menggunakan aplikasi MYOB.

\section{METODOLOGI}

Studi eksplanatori ini menggunakan intervieu semi structured untuk mengumpulkan data dari beberapa pihak yang terkait dengan sistem pengendalian internal kas diantaranya dewan direksi dan bagian keuangan PT. LDP. Di samping itu pengumpulan data juga dilakukan melalui observasi dan analisis dokumen untuk memperkuat analisis data yang dilakukan. Pengumpulan data penelitian dilakukan pada awal tahun 2011 karena merupakan tahap awal evaluasi pengembangan aplikasi MYOB di PT. LDP guna memperkuat sistem informasi pengendalian kasnya.

Prosedur analisis lebih didasarkan pada asersi peneliti karena tidak adanya prosedur standar dalam data kualitatif. O'Dwyer $(2004 ; 391)$ the analytic approach was partly intuitive with the transcriptions being reviewed for common themes and relationships between them categorized. Berdasarkan pendekatan tersebut, hasil wawancara semi structured kemudian dikategorikan untuk menemukan pola permasalahan yang dihadapi perusahaan. Analisis data dilakukan dengan analisis deskriptif kualitatif yang mendiskripsikan data dan informasi yang telah diperoleh melalui pembandingan antara teori yang mendasari dengan praktik sistem informasi akuntansi pengendalian kas di PT.LDP.

\section{HASIL PENELITIAN \\ Sistem Informasi Akuntansi}

Informasi hanya akan berguna jika pihak-pihak yang berkepentingan dapat memahaminya. Secara umum, laporan keuangan sangat kompleks dan detail. 
Kemampuan membaca bahasa akuntansi agar dapat dimengerti oleh umum merupakan sebuah problema untuk beberapa orang. Oleh karena itu diperlukan sistem informasi akuntansi yang dapat dimengerti oleh semua pihak. Berikut merupakan tanggapan dari staf keuangan PT. LDP ;

Bagaimanakah sistem informasi akuntansi yang diterapkan di PT. LDP Yogyakarta? Sebelum tahun 2010, PT.LDP menggunakan sistem spreadsheed excel. Namun dalam perkembangan perusahaan yang semakin pesat, kami mengalami kesulitan untuk menyajikan laporan keuangan tepat waktu. Sehingga keputusan rapat dewan direksi kadang kurang sesuai dengan kodisi finansial perusahaan dan terkadang rapat dewan direksi harus mundur dari jadwal yang telah ditetapkan karena laporan keuangan yang belum selesai dikerjakan.. Oleh karena itu awal tahun 2010 PT. LDP memutuskan untuk mengubah sistem informasi akuntansinya dengan menggunakan MYOB V 13+.

Berdasarkan tanggapan tersebut dapat diketahui bahwa laporan keuangan pada PT. LDP difungsikan dengan baik untuk pengambilan keputusan ekonomik perusahaan. Sedangkan hasil observasi peneliti selama di PT LDP Yogyakarta ditemukan bahwa penggunaan aplikasi MYOB memang sangat mendukung kegiatan pembuatan laporan keuangan. Namun demikian penggunaan informasi laporan keuangan yang dilakukan oleh PT. LDP lebih difokuskan pada laba perusahaan.

Penilaian kinerja perusahaan yang hanya didasarkan pada angka laba sangat rentan karena kemungkinan adanya manajemen laba. Oleh karena itu peneliti kemudian melakuka observasi lebih lanjut dan melakukan analisis dokumen terhadap laporan keuangan PT. LDP. Hasil dari analisis dokumen dan observasi tidak menemukan adanya praktik manajemen laba oleh manajer keuangan karena di PT.LDP manajer merupakan pemilik sebagian saham. Sehingga praktik-praktik penggunaan sistem informasi akuntansi yang tidak sehat tidak ditemukan.

\section{Pengendalian Kas}

Pengendalian kas dari aktivitas operasi mencakup pengawasan penerimaan dan pengeluaran kas. Sistem penerimaan dan pengeluaran kas dalam jumlah besar di PT.LDP langsung ditangani oleh direktur melalui e-banking sedangkan penerimaan dan pengeluaran kas dalam jumlah kecil ditangani oleh bagian administrasi. Untuk memahami sistem otorisasi pengendalian kas PT. LDP, berikut susunan organisasi dan tingkat otorisasinya ;

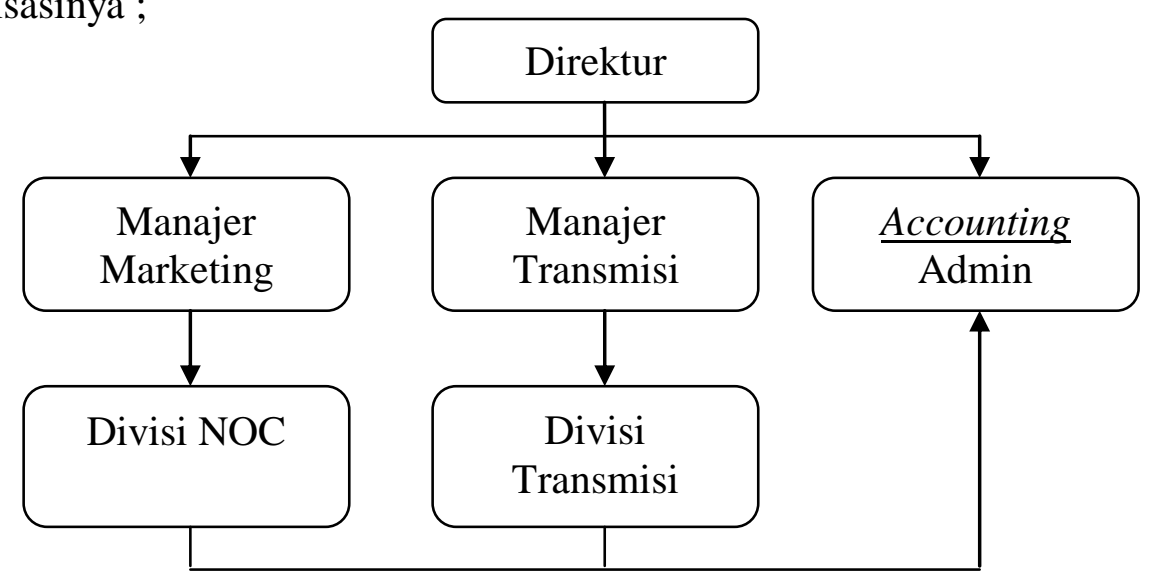


Berdasarkan struktur tersebut, pengendalian kas memang agak lemah karena bagian pencatatan dan pemegang kas menjadi satu pada bagian Admin. Pengeluaran kas yang cukup besar biasanya dilakukan oleh manajer transmisi untuk pembelian alat mikrotik (asset investasi) yang mendapat otorisasi langsung dari direktur melalui transaksi e-banking. Sayangnya pengeluaran ini tidak disampaikan kepada admin sehingga terjadi selisih antara pencatatan dengan kas di bank sebenarnya. Masalah lebih lanjut yang ditimbulkan adalah pengakuan asset perusahaan cenderung underestimate karena pembelian alat mikrotik yang tidak disampaikan kepada admin tidak tercatat dalam neraca sehingga sistem penyusutan yang diterapkan tidak mewakili prinsip matching concept yang harus dipenuhi.

Namun demikian, beberapa kelemahan pengendalian kas tersebut tidak menjadikan tingginya kasus penyelewengan kas di PT. LDP. Karena berdasarkan hasil observasi PT.LDP merupakan perusahaan keluarga. Dimana pemilik saham, direktur, manajer marketing, manajer transmisi serta staf akuntansi memiliki kedekatan hubungan keluarga.

\section{MYOB}

Penggunaan software akuntansi pada umumnya ditujukan untuk kepraktisan mengolah data-data transaksi dan pembuatan laporan keuangan yang memenuhi kriteria timelines. PT. LDP memilih penggunaan MYOB karena software tersebut sangat userfriendly sehingga mudah dimengerti dan fitur-fiturnya yang lengkap dapat mencakup semua tipe entitas usaha. Namun demikian keberhasilan pemakaian sistem aplikasi sangat dipengaruhi oleh user. Ruchyat Suryana $(2009 ; 1)$,menyatakan bahwa “ Tabiat komputer selalu konsekuen. Kalau input benar maka outputnya juga pasti benar, demikian juga sebaliknya. Inilah GIGO Effect; Garbage In Garbage Out, Gold In Gold Out".

Pada tahap intervieu dengan direktur dan staf keuangan secara bersamaan mereka menyatakan bahwa penggunaan aplikasi MYOB sangat membantu.

Apakah penggunaan Aplikasi MYOB mempermudah pembuatan laporan keuangan? Ya, keberadaannya sangat membantu kami dalam menyajikan laporan keuangan sehingga memenuhi kriteria timelines. Kapanpun laporan keuangan itu diperlukan dapat langsung dicetak tanpa prosedur yang rumit. Sehingga apabila terjadi suatu masalah yang mendesak, dapat diambil keputusan ekonomik yang logis.

Selama tahun 2010 pengembangan MYOB di PT.LDP mampu memenuhi kebutuhan informasi perussahaan. Namun demikian pada pertengahan tahun 2011 ditemukan akun pendapatan bernilai negatif. Hal tersebut tentu mengejutkan manajemen serta dewan direksi karena aktivitas perusahaan dalam tahun 2011 sangat tinggi dan secara fisik memberikan kontribusi laba yang lebih besar daripada tahun sebelumnya.

Oleh kaena itu dilakukan penelusuran lebih lanjut mengenai masalah yang terjadi. Setelah diperiksa, ternyata penyebab angka negatif tersebut adalah kesalahan penggunaan aplikasi MYOB dalam penjurnalan dimana penambahan akun pendapatan yang harusnya secara PABU masuk pada kolom kredit, oleh staf keuangan dimasukkan ke kolom debit. Kesalahan berulang beberapa kali ini ternyata membawa dampak yang cukup material bagi penyajian laba perusahaan. Kejadian tersebut konsisten dengan prinsip komputer yang telah disampaikan oleh Ruchyat Suryana diatas. 


\section{KESIMPULAN}

Hasil studi kasus tersebut mendukung argumen peneliti bahwa penerapan sistem informasi akuntansi dengan menggunakan software MYOB dalam beberapa hal dapat meningkatkan kualitas penyajian laporan keuangan jika beberapa kriteria berikut dipenuhi :

1. Penggantian sistem informasi akuntansi memperoleh dukungan dari semua pihak. Termasuk transparansi semua elemen organisasi perusahaan sehingga sistem baru yang diterpkan dapat memberikan informasi sesuai dengan keadaan sebenarnya.

2. Pengendalian internal utamanya penerimaan dan pengeluaran kas harus dirancang dengan baik guna menghindari penggelapan kas. Karena sistem pengendalian yang lemah, tidak dapat memberikan informasi yang akurat walaupun sistem informasi akuntansinya telah dirancang dengan baik.

3. SDM (user) merupakan faktor terpenting dalam penggunaan aplikasi software akuntansi karena pengolahan data computer bersifat GIGO.

\section{SARAN}

Bebrapa saran yang dapat diberikan kepada PT. LDP guna pengembangan sistem informasi lebih lanjut adalah :

1. Sebaiknya prosedur penerimaan dan pengeluaran kas dalam jumlah besar melalui $e$ banking selalu direkap dan dilaporkan kepada staf keuangan sehingga informasi yang dihasilkan dari aplikasi MYOB dapat memberikan gambaran kondisi finansial perusahaan yang sebenarnya yang nantinya dapat dipergunakan pada proses pengambilan keputusan ekonomik secara cepat dan tepat.

2. Perlu adanya peningkatan pengendalian internal perusahaan yang memadai. Walaupun sistem saat ini tidak memberikan dampak buruk bagi perusahaan, namun seiring dengan perkembangan yang semakin pesat memerlukan tingkat pengendalian yang lebih baik.

3. Perlu adanya pendidikan dan latihan lebih lanjut pada staf keuangan agar dapat menjalankan MYOB sesuai dengan prinsip-prinsip akuntansi berterima umum.

\section{KETERBATASAN}

Beberapa keterbatasan penelitian ini adalah :

1. Penelitian ini hanya dilakukan pada satu perusahaan sehingga tidak dapat digeneralisasi pada kasus-kasus perusahaan secara umum.

2. Waktu penelitian yang sangat singkat (6 bulan) sehingga kemungkinan ada beberapa faktor lain yang mempengaruhi sistem informasi akuntansi yang diterapkan PT. LDP namun tidak dapat ditemukan oleh peneliti.

\section{IMPLIKASI}

Berdasarkan studi kasus menggunakan metode kualitatif deskriptif tersebut dapat dikembangkan penelitian mendatang mengenai bagaimanakah sistem pengendalian internal yang baik bagi perusahaan keluarga. Hal ini sangat menarik untuk dikaji lebih lanjut karena beberapa perusahaan besar di Indonesia merupakan bisnis keluarga. 


\section{DAFTAR PUSTAKA}

O’Dwyer, B ; 2004 ; Qualitative data analysis : illuminating a process for transforming a 'messy' but 'attractive' 'nuisance' in Humprey, C and Lee, B (Eds) the real life guide to accounting research a behind the scenes view of using qualitative research methods ; Elsevier ; Oxford, pp 391-407

http://myob.com.au/myob/myob-group/the-myob-story-1258090872813 The MYOB Story diakses pada 18/6/2013 pkl 20.37 WIB

Bodnar, George dan William S.Hopwood ; 2006 ; Sistem informasi Akuntansi ; Yogyakarta ; CV. Andi Offset.

Nugroho Widjajanto ; 2001 ; Sistem informasi kauntansi ; Jakarta ; Erlangga

Ruchyat Suryana ; 2009 ; Komputerisasi Akuntansi dengan MYOB ; Bandung ; Informatika

IAI; 2009 ; ED PSAK 2 Laporan Arus Kas ; www.iaiglobal.or.id/ ; diakses pada 18/06/2013 pkl 20.27 WIB

Ernst Young ; 2012 ; Financial reporting developments A comprehensive guide ; http://www.ey.com/publication/vwluassetsdld/financialreportingdevelopments_42 856_cashflows_may2012/\$file/financialreportingdevelopments_42856_cashflows _may2012.pdf?OpenElement diakses pada 18/06/2013 pkl 20.20 WIB 